(1)
Volume 6, Nomor 2, Tahun 2020
Tersedia Online: http://ojs.uniska.ac.id/index.php/BKA
e-ISSN 2477-6300

\title{
PENGARUH BIMBINGAN KELOMPOK MELALUI WHATSAPP TERHADAP TINGKAT PEMAHAMAN SISWA TENTANG PENYALAHGUNAAN NAPZA DI SMP NEGERI 15 BANJARMASIN
}

\author{
Rizma Yusnita, Muhammad Yuliansyah, Nurmiati \\ Program Studi Bimbingan dan Konseling, Universitas Islam Kalimantan Muhammad Arsyad Al Banjari \\ E-mail : $\underline{\text { rizma804@gmail.com }}$
}

\begin{abstract}
ABSTRAK
Konflik yang sering dialami dikalangan remaja adalah penyalahgunaan NAPZA, yang diantaranta Narkotika, Psikotropika dan Zat-zat Adikitif lainnya. Memakai Napza menimbukan perasaan enak, nikmat, senang, bahagia, tenang dan nyaman, tetapi dapat menimbulkan ketergantungan yang di tandai oleh dorongan untuk menggunakan Napza secara terus menerus dengan takaran yang meningkat agar menghasilkan efek yang sama dan apabila penggunaannya dikurangi atau dihentikan secara tiba-tiba, maka menimbulkan gejala fisik dan psikis yang khas. Penelitian ini bertujuan untuk: a) Untuk mengetahui bagaiman tingkatan pemahaman pada siswa tentang penyalahgunaan napza dan untuk mengetahui ada tidaknya pengaruh bimbingan kelompok melalui whatsapp terhadap tingkat pemahaman siswa, b) Untuk mengetahui pengaruh pelaksanaan bimbingan kelompok melalui whatsapp di SMPN 15 Banjarmasin. Dalam penelitian ini metode yang digunakan peneliti adalah metode pendekatakan kuantitatif. Desain dalam penelitian ini adalah Deskriptif Kunatitatif. Karena hasilnya berupa angka, mulai dari pengumpulan data, penafsiran terhadap data tersebut, serta penamiplan hasilnya. Populasi yang digunakan peneliti dalam penelitian ini adalah kelas VIII F dengan jumlah 29 siswa/i. Sampel yang digunakan peneliti dalam penlitian ini berjumlah 12 siswa yang terdiri diantaranya 10 orang siswa laki-laki dan 2 orang siswa perempuan. Temuan pada penelitian menunjukan: a) terdapat peningkatan terhadap tingkat pemahaman siswa tentang penyalahgunaan NAPZA di SMP Negeri 15 Banjarmasin menggunakan layanan bimbingan kelompok melalui Whatsapp. b) layanan bimbingan kelompok melalui whatsapp secara signifikan memiliki pengaruh terhadap tingkat pemahaman siswa tentang penyalahgunaan NAPZA.
\end{abstract}

Kata Kunci: Penyalahgunaan NAPZA; Tingkat Pemahaman; Bimbingan Kelompok

\begin{abstract}
Conflicts that are often experienced among adolescents are drug abuse, which is accompanied by Narcotics, Psychotropics and other Addictive Substances. Drug use leads to feelings of pleasure, pleasure, pleasure, happiness, calm and comfort, but it can cause dependency which is marked by the urge to use drugs continuously with increasing amounts to produce the same effect and if its use is reduced or stopped suddenly. , then cause physical and psychological symptoms that are typical.This study aints to: a) To find out how the level understanding of student about drug abuse and to determine whether there is influnce of group guidance through whatsapp on the level of student understanding, b)To determine the efffect of implementing group guidance through whatsapp at SMPN 15 Banjarmasin. In this study the method used by researchs is a quantitative approach method. The design in this research is descriptive quantitative. Because the results are in the form of numbers, starting from data collection, interpretation of the data, and analyzing the results. The population used by researchers in this study was class VIII F with a total of 29 student. The sample used by researchers in this study amounted to 12 students consisting of 10 male students and 2 female students. The finding of the study showed: a) there was an increase in the level of students understanding of drugs abuse in SMP 15 Banjarmasin using group guidance services through Whatsapp, b)group guidance services through Whatsapp significantly have an influence on students level of understanding about drug abuse.
\end{abstract}

Keywords: Drug Abuse; Level of Understanding; Group Guidance 


\section{PENDAHULUAN}

NAPZA disebut dengan istilah Napza yang merupakan kependekan dari Narkotika, Psikotropika, dan Bahan Berbahaya lain. Napza berasal dari bahasa inggris yaitu narcotics, yang berarti obat bius. Definisi Narkotika adalah zat atau obat, baik yang berasal dari tanaman, sintesis, maupun semi sintesis, yang dapat menyebabkan penurunan atau perubahan kesadaran, hilangnya rasa, mengurangi sampai menghilangkan rasa nyeri dan menimbulkan ketergantungan. Adapun yang dimaksud narkotika menurut Undang-undang nomor 35 tahun 2009 tentang narkotika pasal 1 angka 1 adalah sebagai berikut :

"Narkotika adalah zat atau obat yang berasal dari tanaman atau bukan tanaman, baik sintesis maupun semisintesis yang dapat menyebabkan penurunan atau perubahan kesadaran, hilangnya rasa, mengurangi sampai menghilangkan rasa nyeri, dan dapat menimbulkan ketergantungan, yang dibedakan dalam golongangolongan sebagaimana terlampir dalam undangundang".

Tentang psikotropika itu sendiri diatur dalam Undang-undang nomor 5 tahun 1997 tentang psikotropika pasal 1 angka 1 :

"Psikotropika adalah obat baik alamiah maupun sintesis bukan narkotika, yang berkhasiat psikoaktif melalu pengaruh selektif pada susuan syaraf yang menyebabkan perubahan khas pada aktifitas mental dan perilaku."

World Drugs Reports 2018 dari United Nation Office on Drugs and Crime (UNODC) : 275 juta penduduk di dunia atau 5,6\% dari penduduk dunia (usia 15 - 64 tahun) pernah mengkonsumsi Napza. Sedangkan angka penyalahgunaan Napza di kalangan pelajar pada tahun 2018 (dari 13 Ibukota Provinsi di Indonesai) mencapai angka 2,29 juta orang. Salah satu kelompok masyarakat yang rawan terpapar penyelahgunaan Napza adalah mereka yang berada pada rentang usia 15- 35 tahun atau generasi milenial.

Sedangakan isu tentang penyakahgunaan napza sudah menyebar luas di dunia pendidikan. Untuk itu, menghadapi persoalan napza pada dunia pendidikan memiliki peranan dalam pencegahannya. Kontribusi pendidikan yang diharapkan bagi perkembangan para peserta didik yang tertera dalam Undang-undang No. 20 tahun 2003 Bab II Pasal 3, sebagai berikut :

"Pendidikan nasional berfungsi untuk mengembangkan kemampuan dan membentuk watak serta peradaban bangsa, bertujuan untuk berkembangnya potensi peserta didik agar menjadi manusia yang beriman dan bertaqwa kepada Tuhan Yang Maha Esa, berakhlak mulia, sehat, berilmu, cakap, kreatif, mandiri dan menjadi warga Negara yang demokratis serta bertanggung jawab".

Berdasarkan data dari buletin jendela dari kementrian kesehatan RI terjadi peningkatan jumlah kasus penyalahgunaan Napza di provinsi Kalimantan selatan pada tahun 2010 sebanyak 534 kasus, 2011 sebanyak 887 kasus, dan 2012 sebanyak 1.188 kasus. Sedangkan untuk di Banjarmasin pada Januari hingga Desember 2019 tercatat sebanyak 38.680 pengguna Napza dalam penanganan Pencegahan dan Pemberdayaan Masyarakat Badan Narkotika (BNN) Kota Banjarmasin. Menurut kepala BNN Kota Banjarmasin, Kompol H Syamsudin SE, dalam sebuah artikel berita online.

Penyalahgunaan narkotika, psikotropika, dan zat adiktif lainnya semakin marak di Indonesai. Maraknya narkotika dan obat-obatan terlarang telah banyak mempengaruhi mental dan sekaligus pendidikan bagi para pelajar saat ini. Anak merupakan generasi muda penerus cita-cita bangsa dan merupakan sumber daya manusia bagi pembangunan nasional. Anak dalam pemaknaan yang umum mendapat perhatian baik dalam bidang ilmu pengetahuan, agama, hukum dan sosiologi yang menjadikan pengertian anak semakin aktual dalam lingkungan sosialnya.(Sarwono, 2012)

Ditengah pandemic Covid-19 sekarang ini, pembelajaran online sangat diutamakan untuk keberlangsungan dalam dunia pendidikan. Pemberian informasi serta ilmu pendidikan pun semuanya dilakukan melalui media online maupun televisi atau media lainnya yang bisa memberikan informasi serta ilmu pendidikan yang diperlukan siswa. Perkembangan teknologi informasi yang semakin pesat di era globalisasi saat ini tidak bisa dihindari lagi pengaruhnya terhadap dunia pendidikan. Menurut Hamzah dan Nina Lamatenggo, (2011, 61). Mengatakan bahwa kecenderungan pendidikan di Indonesia di masa mendatang adalah sebagai berikut :

1. Berkembangnya pendidikan terbuka dengan modus belajar jarak jauh (distance learning). Kemudian untuk menyelenggarakan pendidikan terbuka dan jarak jauh perlu dimasukan sebagai strategi utama.

2. Sharing resource bersama antar lembaga pendidikan/latihan dalam sebuah jaringan perpustakan dan instrument pendidikan lainnya (guru, laboratorium) berubah fungsi menjadi sumber informasi daripada sekedar rak buku.

3. Penggunaan perangkat teknologi informasi interaktif, seperti CD-ROOM multi media dalam pendidikan secara bertahap menggantikan televisi dan video.

Dan dalam permasalahan ini teknologi yang digunakan untuk memberikan informasi kepada 
Rizma Yusnita, Muhammad Yuliansyah, Nurmiati

Jurnal Bimbingan dan Konseling Ar-Rahman

Volume 6, Nomor 2, Tahun 2020

e-ISSN 2477-6300

siswa ditengah pandemic Covid-19 ini media Chat Group pada Whatsapp menjadi pilihan yang paling sering digunakan oleh guru-guru untuk memberikan informasi ataupun tugas-tugas yang berhubungan dengan perkembangan pembelajaran siswa selama dirumah saja.

Dengan adanya perkembangan teknologi dan informasi dalam dunia pendidikan, maka pada saat itu sudah dimungkinkan untuk diadakan belajar jarak jauh dengan menggunakan media internet untuk menghubungkan antara siswa dengan gurunya. Dan juga pemberian layanan informasi mengenai dunia pendidikan maupun proses belajar mengajar bisa tetap dijalankan sebagaimana mestinya. Karena pada umumnya siswa SMP adalah anak-anak atau remaja yang sudah mulai tumbuh rasa keingin tahuannya, oleh sebab itu ditengah pandemic Covid-19 ini berbagai upaya bisa dilakukan untuk memberikan informasi kepada siswa salah satunya melalui media teknologi informasi dan komunikasi online, termasuk dalam memberikan informasi mengenai Napza.

Konflik yang sering dialami dikalangan remaja adalah penyalahgunaan NAPZA, yang diantaranya Narkotika, Psikotropika dan Zat-zat Adikitif lainnya. Memakai Napza menimbulkan perasaan enak, nikmat, senang, bahagia, tenang dan nyaman, tetapi dapat menimbulkan ketergantungan yang di tandai oleh dorongan untuk menggunakan Napza secara terus menerus dengan takaran yang meningkat agar menghasilkan efek yang sama dan apabila penggunaannya dikurangi atau dihentikan secara tiba-tiba, maka menimbulkan gejala fisik dan psikis yang khas.

Melihat dari adanya peningkatan pengguna Napza di kalangan pelajar SMP yang terus meningkat dari tahun ke tahun, serta banyaknya dampak atau bahaya yang ditimbulkan dari penyalahgunaan Napza, untuk itu penulis ingin mengurangi kecenderungan penggunaan Napza dikalangan pelajar di SMP Negeri 15 Banjarmasin. Hasil dari observasi penulis selama pelaksanaan PLP II dan hasil dari wawancara terhadap guru BK di SMP Negeri 15 Banjarmasin ini terdapat satu kasus dimana siswanya kedapatan mengkonsumsi obat-obatan terlarang saat pergi berlibur bersama teman satu sekolahnya.

Dalam kejadian tersebut 26 anak 10 orang diantaranya mengkonsumsi zat adiktif selama perjalanan wisata. Guru BK SMP Negeri 15 Banjarmasin sudah melakukan banyak usaha untuk menghindarkan siswanya dari Napza dan bahan yang mengandung zat adiktif, dengan memberikan pemahaman tentang apa dan bagaimana dampak Napza bagi tubuh, baik itu dengan cara mengobrol santai atau siswa dipanggil keruang BK untuk diberi pengertian serta konseling individual ataupun konseling kelompok tentang bahaya Napza bagi remaja, memanggil orang tua yang bersangkutan untuk bersama-sama mendiskusikan dan mencari jalan keluar yang baik bagi anak-anak mereka. Namun tindakan yang dilakukan oleh guru BK maupun guru-guru tersebut masih kurang optimal karena masih ada saja siswa yang kedapatan mengulangi hal yang sama setelahnya, dan guru juga belum melakukan tindakan pencegahan terhadap siswa yang tidak menyalahgunakan Napza disekolah tersebut.

Berdasarkan hasil observasi dilapangan selama melaksanakan PLP II dampak lain yang ditimbulkan dari penyalahgunaan Napza adalah adanya pergaulan bebas siswa yang dapat menyebabkan munculnya penyimpangan terhadap norma-norma. Untuk penyalahgunaan Napza ini terjadi karena faktor keluarga, lingkungan social, serta kurangnya pemahaman siswa tentang bahawa penyalahgunaan Napza.

Tindakan penanganan terhadap siswa yang telah menyalahgunaakan Napza dilakukan oleh guru BK disekolah ini. Namun, siswa yang tidak melakukan penyalahgunaan Napza juga perlu diberikan layanan berupa tindakan pencegahan agar dikemudian hari tidak menyalahgunakan Napza dan diberikan pemahaman tentang dampak buruk yang ditimbulkan akibat penyalahgunaan Napza, akan tetapi hal ini belum sepenuhnya dilakukan oleh guru BK disekolah tersebut. Adapun tindakan yang dilakukan guru BK disekolah tersebut untuk mencegah siswa yang tidak menyalahgunakan Napza dengan secara tidak langsung memberikan peringatan tentang dampak Napza, akan tetapi hal tersebut dirasa penulis kurang efektif dan kurang memberikan hasil yang maksimal, mengingat banyaknya pemahaman serta penjelasan tentang bahaya Napza bagi pelajar.

Adapun Hipotesis pada penelitian ini sebagai berikut : hipotesis yang pertama adalah layanan bimbingan kelompok melalui Whatsapp secara signifikan tidak berpengaruh dalam tingkat pemahaman siswa tentang penyalahgunaan napza di SMP Negeri 15 Banjarmasin, karena ada kemungkinan dipengaruhi beberapa factor yang membuatnya jadi tidak efektif. Hipotesis yang kedua adalah layanan bimbingan kelompok melalui Whatsapp secara signifikan memiliki pengaruh dalam tingkat pemhaman siswa tentang penyalahgunaan napza di SMP Negeri 15 Banjarmasin.

\section{METODE}

Dalam penelitian ini metode yang digunakan peneliti adalah metode pendekatakan kuantitatif. Karena hasilnya berupa angka, mulai 
Rizma Yusnita, Muhammad Yuliansyah, Nurmiati Jurnal Bimbingan dan Konseling Ar-Rahman Volume 6, Nomor 2, Tahun 2020

e-ISSN 2477-6300

dari pengumpulan data, penafsiran terhadap data tersebut, serta penamiplan hasilnya. Menurut Izaak Latanussa dalam Sudjana (2004: 40) "Penelitian kuantitatif yaitu penelitian yang menggunakan metode bilangan untuk mendeskripsikan observasi suatu objek atau variabel dimana bilangan menjadi bagian dari pengukuran".

Dengan pendekatan menggunakan desain Kuantitatif eksperimen. Menurut Sugiyono (2012: 29) pengertian deskriptif adalah sebagai metode yang berfungsi untuk mendeskripsikan atau memberi gambaran terhadap objek yang diteliti melalui data atau sampel yang telah terkumpul sebagaimana adanya, tanpa melakukan analisis dan membuat kesimpulan yang berlaku umum.

Populasi yang digunakan peneliti dalam penelitian ini adalah kelas VIII F dengan jumlah 29 siswa/i. Dengan teknik pengumpulan sampel menggunakan teknik Purposive Random Sampling. Sampel yang digunakan peneliti dalam penlitian ini berjumlah 12 siswa yang terdiri diantaranya 10 orang siswa laki-laki dan 2 orang siswa perempuan, dimana jumlah ini digunakan untuk layanan bimbingan kelompok yang minimal anggotanya berjumlah 12 orang saja.

\section{HASIL DAN PEMBAHASAN}

Gambaran tingkat pemahaman siswa tentang penyalahgunaan NAPZA melalui pretest dan posttest dapat dilihat pada table total skor dari pretest dan posttest berikut.

Tabel 1. Skor Total pada Pretest dan Posttest

\begin{tabular}{ccc}
\hline Subyek & Pretest & Posttest \\
\hline 1 & 28 & 38 \\
2 & 25 & 38 \\
3 & 22 & 29 \\
4 & 29 & 35 \\
5 & 30 & 39 \\
6 & 32 & 39 \\
7 & 30 & 32 \\
8 & 25 & 29 \\
9 & 30 & 32 \\
10 & 30 & 37 \\
11 & 14 & 20 \\
12 & 31 & 37 \\
\hline Total Data & $\mathbf{3 5 7}$ & $\mathbf{4 4 2}$ \\
\hline
\end{tabular}

Dari total 12 responden, pada pretest terdapat 1 responden yang memiliki tingkat pengetahuan yang rendah tentang napza yaitu dengan total nilai skor 14 item dengan jawaban benar dari total keseluruhan 40 item. Dan setelah diberikan layanan informasi melalui bimbingan kelompok dengan media Whatsapp tingkat pengetahuannya meningkat menjadi total skor 20 item dengan jawaban benar dari total 40 item.

Sebelum melakukan pengujian pada hipotesis ada beberapa uji persyaratan yang harus dilakukan untuk dapat menghitung signifikansi pengaruh pada variabel penelitian, yaitu sebagai berikut :

1) Uji normalitas

Salah satu persyaratan analisis yang harus dipenuhi agar dapat menggunakan analisis regresi adalah selebaran data dari setiap variabel harus normal. Pada penelitian ini peneliti menguji normalitas dari pretest dan posttest. Hasil uji normalitas dapat dilihat pada table berikut :

Tabel 2. One-Sample Kolmogorov-Smirnov Pre-Test

\begin{tabular}{llr} 
& & Pre test \\
N & & 12 \\
& Mean & 28.17 \\
& Std. & 3.973 \\
Most Extreme & Deviation & \\
Differences & Absolute & .178 \\
& Positive & .124 \\
Test Statistic & Negative & -.178 \\
Asymp. Sig. (2-tailed) & & .178 \\
\hline
\end{tabular}

a. Test distribution is Normal.

Pada pengujian normalitas pretest dapat dilihat bahwa nilai Asymp, Sig. (2-tailed) bernilai $0,200>0,05$ maka dapat dikatakan data pretest berdistribusi normal.

Tabel 3. One-Sample Kolmogorov-Smirnov Post-Test

\begin{tabular}{llr} 
& & Post test \\
\hline $\mathrm{N}$ & & 12 \\
Normal Parameters & & \\
& Mean & 33.75 \\
& Std. Deviation & 5.675 \\
Most Extreme & Absolute & .217 \\
Differences & Positive & .177 \\
& Negative & -.217 \\
Test Statistic & & .217 \\
Asymp. Sig. (2-tailed) & & $.126^{\mathrm{c}}$ \\
\hline
\end{tabular}

a. Test distribution is Normal.

Gambar diatas merupakan hasil perhitungan dari uji normalitas posttest dan dapat dilihat dari Asymp, Sig. (2-tailed) bernilai 0,126 > 0,05 artinya data posttest berdistribusi normal. 
Rizma Yusnita, Muhammad Yuliansyah, Nurmiati

Jurnal Bimbingan dan Konseling Ar-Rahman

Volume 6, Nomor 2, Tahun 2020

e-ISSN 2477-6300

2) Uji homogenitas

Uji ini bertujuan untuk mengetahui apakah variasi beberapa data dari populasi memiliki varians yang sama atau tidak. Adapun dasar pengambilan keputusan dalam uji homogenitas, yaitu :

a. Jika nilai signifikansi (Sig.) $<0,05$ maka dikatakan bahwa varians dari dua atau lebih kelompok populasi data adalah tidak sama (tidak homogen).

b. Jika nilai signifikansi (Sig.) > 0,05 maka dikatakan bahwa varians dari dua atau lebih kelompok populasi data adalah sama (homogen).

\section{Tabel 4. Uji Homogenitas}

\begin{tabular}{lccccc}
\hline & Sum of & \multicolumn{4}{c}{ Mean } \\
& Squares & df & Square & F & Sig. \\
\hline Between & 275.750 & 7 & 39.393 & 2.007 & .261 \\
Groups & & & & & \\
Within & 78.500 & 4 & 19.625 & & \\
Groups & & & & & \\
\hline Total & 354.250 & 11 & & \\
\hline
\end{tabular}

Berdasarkan hasil perhitungan menggunakan SPSS dapat dilihat nilai Sig. yaitu 0,261 > 0,05 dapat dikatakan bahwa varians kelompok populasi pada data ini adalah sama (homogen).

3) Pengujian hipotesis menggunakan Uji linieritas regresi sederhana dan Uji $t$

Analisis ini bertujuan untuk mengukur besarnya pengaruh satu variabel bebas terhadap variabel terikat. Adapun yang menjadi dasar pengambilan keputusan dalam analisis regresi dengan melihat nilai signifikansi (Sig.) hasil output SPSS adalah :

a. Jika nilai signifikansi (Sig.) $<0,05$ artinya terdapat pengaruh antara variabel bebas terhadap variabel terikat.

b. Jika nilai signifikansi (Sig.) $>0,05$ artinya tidak ada pengaruh antara variabel bebas terhadap variabel terikat.

Hasil pengujian hipotesis dapat dilihat pada tabel 5 dan 6. Dari hasil perhitungan pada tabel 5 di atas jika dilihat dari nilai signifikansi (Sig.) $0,001<0,05$ maka dapat dikatakan bahwa terdapat pengaruh antara pretest dan posttest terhadap tingkat pemahaman siswa tentang NAPZA. Maka $\mathrm{H}_{1}$ diterima dan $\mathrm{H}_{0}$ di tolak, yaitu layanan bimbingan kelompok melalui whatsapp secara signifikan memiliki pengaruh dalam tingkat pemahaman siswa tentang penyalahgunaan NAPZA di SMP Negeri 15 Banjarmasin.

Tabel 5. Coefficients ${ }^{a}$

\begin{tabular}{cccccc}
\hline $\begin{array}{c}\text { Unstandardized } \\
\text { Coefficients }\end{array}$ & \multicolumn{2}{c}{$\begin{array}{c}\text { Standardized } \\
\text { Coefficients }\end{array}$} & & \\
\cline { 1 - 2 } \multicolumn{2}{c}{ Std. } & & & \\
B & Error & Beta & T & Sig. \\
\hline 8.419 & 5.376 & & 1.566 & .148 \\
.932 & .195 & & .834 & 4.787 & .001 \\
\hline
\end{tabular}

a. Dependent Variable: Posttest

Tabel 6. ANOVA

\begin{tabular}{lcccccc} 
& Sum of & \multicolumn{3}{c}{ Mean } & & \\
Model & Squares & df & Square & F & Sig. \\
\hline Regression & 246.628 & 1 & 246.628 & 22.91 & $.001^{\text {b }}$ \\
Residual & 107.622 & 10 & 10.762 & & \\
\hline Total & 354.250 & 11 & & & & \\
\hline
\end{tabular}

a. Dependent Variable: Posttest

b. Predictors: (Constant), Pretest

Berdasarkan output SPSS diketahui nilai $\mathrm{t}$ hitung sebesar 4,787. Dan untuk mengetahui nila t table maka dapat dilihat dari table ANOVA pada bagian Residual dan nilai $d f$ yaitu menunjukan nilai 10 dan dapat dilihat pada distribusi nilai t table dengan $\mathrm{t} 0,05=1,812$. Dan berdasarkan dasar pengambilan keputusan dengan membandingkan nilai $\mathrm{t}$ hitung dan $\mathrm{t}$ table, maka $\mathrm{t}$ hitung 4,787 $>\mathrm{t}$ table 1,812 kesimpulannya bahwa $\mathrm{H}_{1}$ diterima. Artinya ada pengaruh yang signifikan antara layanan bimbingan kelompok menggunakan media whatsapp terhadap tingkat pemahaman siswa tenang penyalahgunaan NAPZA.

Berdasarkan hasil analisis yang dilakukan menggunakan teknik analisis regresi linear sederhana terbukti terdapat pengaruh antara layanan bimbingan kelompok melalui whatsapp terhadap tingkat pemahaman siswa tentang NAPZA di SMP Negeri 15 Banjarmasin, yaitu dengan melihat skor nilai signifikansi perhitungan pada SPSS (Sig.) $0,0001<0,05$. Maka dapat disimpulkan bahwa $\mathrm{H}_{1}$ diterima, artinya ada pengaruh layanan bimbingan kelompok melalui whatsapp terhadap tingkat pemahaman siswa tentang NAPZA. 
Rizma Yusnita, Muhammad Yuliansyah, Nurmiati Jurnal Bimbingan dan Konseling Ar-Rahman Volume 6, Nomor 2, Tahun 2020

e-ISSN 2477-6300

Kemudian jika berdasarkan perbandingan nilai $\mathrm{t}$ hitung dengan $\mathrm{t}$ table, yaitu : berdasarkan hasil analisis yang dilakukan dengan regresi linear sederhana dengan melihat nilai t hitung pada table perhitungan Coefficients pada nilai t hitung sebesar 4,787 > t table 1,812. Maka dapat disimpulkan bahwa $\mathrm{H}_{1}$ diterima, artinya ada pengaruh layanan bimbingan kelompok melalui whatsapp terhadap tingkat pemahaman siswa tentang NAPZA.

Meskipun secara signifikan terdapat pengaruh terhadap tingkat pemahaman siswa, layanan bimbingan kelompok melalui whatsapp dinilai peneliti kurang efektif dilakukan karena beberapa siswa tidak bisa aktif dalam proses pemberian layanan dan hanya menjadi pembaca saja dalam grup chat tersebut sehingga tidak adanya dinamika kelompok didalamnya. Penggunaan media whatsapp menjadi salah satu alterantif yang bisa digunakan untuk memberikan informasi kepada siswa ditengah pandemic saat ini, walaupun ada beberapa kendala yang dialami peneliti. Seperti sulit mengumpulkan siswa yang akan dijadikan sampel dikarenakan ada beberapa siswa yang tidak memiliki ponsel dan juga ada yang tidak aktif dalam pemberian layanan bimbingan kelompok tersebut.

Peneliti menyadari bahwa dalam penelitian ini terdapat beberapa keterbatasan, walaupun berbagai upaya telah dilakukan untuk mencapai hasil yang maksimal untuk mengungkapkan tujuan penelitian ini. Namun demikian peneliti menyadari adanya keterbatasan yang diduga dapat memberikan kekurangan. Keterbatasan tersebut dapat berupa sulitnya mengukur secara tepat pengaruh layanan bimbingan kelompok melalui whatsapp terhadap tingkat pemaham siswa tentang NAPZA yang hanya diukur menggunakan angket yang disebarkan melalui Google Form karena terkendala pandemic yang dihadapi saat ini.

\section{PENUTUP}

Berdasarkan hasil penelitian yang diuraikan pada BAB IV dapat disimpulkan bahwa ada Pengaruh Layanan Bimbingan Kelompok melalaui Whatsapp terhadap Tingkat Pemahaman Siswa tentang Penyalahgunaan NAPZA di SMP Negeri 15 Banjarmasin. Dari populasi yang diambil dari kelas VIII $\mathrm{H}$ dan kemudian sampelnya sebanyak 12 orang. Hal ini dapat dilihat dari dasil penelitian uji regresi linear sederhana dan juga uji t untuk mengetahui ada atau tidaknya pengaruh layanan bimbingan kelompok melalui whatsapp terhadap tingkat pemahaman siswa tentang penyalahgunaan NAPZA.

Hasil analisis yang dilakukan menggunakan teknik analisis regresi linear sederhana terbukti terdapat pengaruh antara layanan bimbingan kelompok melalui whatsapp terhadap tingkat pemahaman siswa tentang NAPZA di SMP Negeri 15 Banjarmasin, yaitu dengan melihat skor nilai signifikansi perhitungan pada SPSS (Sig.) 0,0001 $<0,05$. Maka dapat disimpulkan bahwa $\mathrm{H}_{1}$ diterima, artinya ada pengaruh layanan bimbingan kelompok melalui whatsapp terhadap tingkat pemahaman siswa tentang NAPZA.

Kemudian jika berdasarkan perbandingan nilai t hitung dengan t Tabel, yaitu : berdasarkan hasil analisis yang dilakukan dengan regresi linear sederhana dengan melihat nilai t hitung pada Tabel perhitungan Coefficients pada nilai t hitung sebesar 4,787 > t Tabel 1,812. Maka dapat disimpulkan bahwa $\mathrm{H}_{1}$ diterima, artinya ada pengaruh layanan bimbingan kelompok melalui whatsapp terhadap tingkat pemahaman siswa tentang NAPZA.

Penelitian ini memiliki banyak kekurangan, dan penulis berharap penelitian ini dapat membantu serta menambah ilm pendidikan baru tentang pemberian layanan informasi melalui bimbingan kelompok dengan media Whatsapp ditengah pandemisaat ini.

\section{REFERENSI}

Afreyanti, L. (2013). Efektivitas Penggunaan Metode Cooperative Learning Tipe Jigsaw Untuk Meningkatkan Hasil Belajar Persiapan Pengolahan Pada Siswa Kelas X SMK Negeri 4 Yogyakarta. Skripsi. Yogyakarta: Fakultas Teknik Universitas Negeri Yogyakarta.

Aisiy, P, N, H. (2016). Meningkatkan Pemahaman Siswa Tentang Bahaya Penyalahgunaan Narkoba Melalui Layanan Informasi Pada Siswa Kelas VIII Di SMP Negeri 34 Semarang Tahun Ajaran 2015/2016. Skripsi. Semarang: Fakultas Ilmu Pendidikan Universitas Negeri Semarang.

Arikunto. (2006). Prosedur Penelitian. Jakarta: Rineka Cipta

Aryusdi, S, W, M. (2016). Peran Guru BK dalam Mencegah Penyalahgunaan Narkoba Dengan Menggunakan Layanan Informasi dan Layanan Bimbingan Kelompok Di Kelas XII SMK Negeri 5 Padang. Skripsi. Padang: Sekolah Tinggi Keguruan dan Ilmu Pengetahuan Sumatera Barat.

Astuti, T. (2017). Kolaborasi Guru BK Dengan Polisi Dalam Mencegah Penyalahgunaan Narkoba di SMP N 15 Yogyakarta. Skripsi. Yogyakarta: Fakultas Dakwah dan Komunikasi Universitas Islam Negeri Sunan Kalijaga.

Hidayat, F. (2016). Dampak Sosial Penyalahgunaan Narkoba Pada Remaja Di Kelurahan 
Rizma Yusnita, Muhammad Yuliansyah, Nurmiati

Jurnal Bimbingan dan Konseling Ar-Rahman

Volume 6, Nomor 2, Tahun 2020

e-ISSN 2477-6300

Kalabbirang Kecamatan Pattallassang Kabupaten Takalar. Skripsi. Makassar: Fakultas Dakwah dan Komunikasi UIN Alauddin

Isjoni. (2011). Pembelajaran Kooperatif. Meningkatkan Komunikasi antar Peserta Didik. Yogyakarta: Pustaka Pelajar.

Lisa, J. \& Sutrisna, N. (2013). Narkoba, Psikotropika dan Gangguan Jiwa. Yogyakarta: Nuha Medika

Maaruf, A. (2018). Pendekatan Studi Islam Dalam Rehabilitasi Penyalahgunaan Narkoba. Institut Agama Islam Negeri Purwokerto. Jurnal Penelitian Agama, 19(2), 30-47.

Masrokhah, U. (2017). Efektivitas Layanan Bimbingan Klasikal Menggunakan Teknik Sosiodrama Dalam Meningkatkan Keterampilan Komunikasi Interpersonal. Skripsi. Yogyakarta: Fakultas Keguruan dan Ilmu Pendidikan Universitas Sanata Dharma

Ningsih, S., Kurniah, N., Delrefi, D. (2016). Penerapan Cooperative Learning untuk Meningkatkan Kemampuan Kognitif.

Pertiwi, E, W. (2017). Efektivitas Layanan Bimbingan Klasikal Dengan Pendekatan Experiental Learning Menggunakan Media Gambar Untuk Meningkatkan Konsep Diri. Skripsi. Yogyakarta: Fakultas Keguruan dan Ilmu Pendidikan Universitas Sanata Dharma.

Pratiwi, JS., Sismiati, A., Siwabessy, L. (2012). Penerapan Model Cooperative Learning Teknik Jigsaw Dalam Layanan Bimbingan Klasikal Terhadap Pemahaman HIV AIDS. INSIGHT: Jurnal Bimbingan dan Konseling, 1(1), 73-78.

Priyambada, S. (2010). Penanggulangan Penyebaran Narkoba Di Kalangan Anak. Media Neliti (Online), diakses melalui: https://media.neliti.com/media/publicatio ns/170748-ID-penanggulanganpenyebaran-narkoba-di-kal.pdf

Sari, K., Setiyowati, E, Indrawati, A, S. (2014). Pengaruh Penerapan Metode Cooperative Learning Model Jigsaw Pada Layanan Bimbingan Klasikal Terhadap Pemahaman Self Regulated Learning. INSIGHT: Jurnal Bimbingan dan Konseling, 3(2), 63-69.

Setiyawan, W. B. M. (2014). Upaya Pencegahan Terhadap Penyebaran Narkoba Di Kalangan Pelajar. Prosiding Seminar Narkoba. Surakarta: Fakultas Hukum Universitas Surakarta.

Slavin. (2010). Cooperative Learning (Teori, Riset, dan Praktek). Bandung: Nusa Media.
Sowanto, D, A. (2013). Survey Tentang Pemahaman dan Sikap Siswa Terhadap Narkoba atau Napza Di Kalangan Remaja. Skripsi. Bandung: Universitas Pendidikan Indonesia.

Sugiyono. (2010). Metode Penelitian Pendidikan. Alfabeta: Bandung

Sumaila, I. (2011). Peranan Pendidikan Islam Dalam Mencegah Bahaya Narkoba Kec. Poso Kota Selatan. Skripsi. Makasar: Univeristas Islam Negeri Alauddin.

UU No. 20 tahun 2003 Bab II Pasal 3

UU No. 22 tahun 1997 tentang Narkotika

UU No. 35 tahun 2009 tentang narkotika pasal 1 angka 1

UU No. 5 tahun 1997 tentang psikotropika pasal 1 angka 1

Wilis, S.S. (2010). Remaja dan Masalahnya. Bandung: Alfabeta

Yusramita. (2013). Upaya Guru Pembimbing dalam Pencegahan Penyalahgunaan Narkoba Dikalangan Siswa di Sekolah Menengah Atas (SMA) Sederajat Se Kecamatan Tampan. Skripsi. Fakultas Tarbiyah dan Keguruan. Pekanbaru: Universitas Islam Negeri Sultan Syarif Kasim Riau. 